contusions of the cranial bones and gunshot depressed fractures of the skull. Such complication was, however, comparatively rare, as there are only three such cases reported in the 363 cases of depressed gunshot fractures of the skull. Only twenty-two cases of erysipelas supervening after gunshot wounds limited to the integuments of the cranium are reported; eight of these terminated fatally. The precise features of these secondary complications are not reported. The author of this great work infers from the prescriptions used that meningitis or some form of encephalitis must have supervened that induced the fatal results. This is very doubtful, as the autopsy of but one case is mentioned, and the report only states that "the liver, spleen, and mesenteric glands were found enlarged."

Aitken, in his Science and Practice of Medicine, vol. i., p. 339, says that: " Extension of the inflammation to the membranes of the brain sometimes takes place, while the external inflammation continues. This untoward event is followed by delirium and coma. But delirium frequently supervenes in the course of erysi. pelatous attacks, independently of any metastasis or extension of the disease to the membranes of the brain." He also says fatal cases terminate by coma, and with dissipated habits, or in dilapidated constitutions, the delirium resembles that of delirium tremens not due to infammation of the brain, but in consequence of an altered condition of the blood and of the nervous system." He cites Barclay in support of this last remark. It will also be remembered in the case reported that there was no marked delirium resembling that of mania à potu, and positively there was no coma. The death was sudden and unexpected, just as Watson says a case may so terminate, though not by apnca, which is sometimes the cause, according to this las authority. The patient formerly had been of irregular habits, and his constitution had greatly been impaired. As nearly all authorities agree that an altered condition of the blood by certain morbific or toxic atoms is always an important factor in such cases, it seems but reasonable to infer that the sudden death must have been due, as said before, to the gradual accumulation of serum under the arachnoid. This must have been going on during Thursday and Friday, and after attaining to a certain quantity, in connection with a feeble heart and an altered state of the blood, immediately arrested the fuuctions of the brain.

\section{SURGICAL TREATMENT OF HOPELESS CASES OF MASTURBATION AND NOCTURNAL EMIS- SIONS.}

\section{BT TIMOTHY HAXNES, M. D., CONCORD, N. H.}

LiKe many others in general practice I am frequently called upon to care for the victims of selfabuse.

While I always strive to help this perverted state of the mind by advice and treatment, by counseling marriage, perbaps, and at times even the immorality of a mistress, stifl there are cases so utterly desperate, so destroyed mentally and physically, that I have been led to face the question, Cannot help be given at the expense of the procreative powers?

The scar of castration is a stigma.

It was with a view of avoiding this deformity that $I$ was led to remove parts of the spermatic ducts in place of the testicles. The operation, which was the same in all three cases reported below, was as follows:-

An incision midway between the external inguinal ring and the testis laid bare the duct, from which a half inch was resected, and the slight wound closed by sutures.

CASE I. E., aged eighteen, a confirmed masturbator, was admitted to the New Hampshire Asylum for the Insane September 4, 1843, and discharged relieved the 25 th of March following.

Readmitted July 2, 1845, and discharged October $2 d$.

His condition seemed to be beyond medical aid, and I was asked to see him to consider the feasibility of castration. I advised resection of the duct, which was assented to, and $I$ did the operation according to the above method.

The patient, living in a distant part of the State, passed out from under my own observation after the operation. From others I learn that while he never fully recovered from his demented state, still he was so far relieved by the treatment that he became a very useful farm hand.

He died in 1881.

CASE II. Mr. L., aged thirty-six, had been addicted to masturbation and had suffered from nocturnal emissions for several years. His mind was so disordered as to render him totally unfit for any business. Starting on a journey, he was more than likely to turn up miles from the place he intended to reach.

I operated March 21, 1872. This patient lives near me, and has been kept under observation.

Soon after the operation he began to improve in flesh and strength, and is now a correct, healthy business man. His testicles are normal as to size and appearance, but the sexual desire is entirely destroyed.

Case III. I was called July 27, 1878, in consultation to see Mr. S., aged thirty, who had practiced selfabuse for years, suffered from nocturnal emissions, and was such a physical wreck that he was unable even to walk without assistance.

When seen he was much emaciated, and had been confined to his room for months. While he could hardly be classed as insane, still his mind was evidently impaired, and at times it was difficult to get him to take sufficient food.

I resected the ducts, and learn from his physician that he improved greatly in flesh and strength after the operation.

He died February 22, 1882, without medical attendance.

By this simple operation, leaving behind it no deformity of the genitals, we have succeeded in all three cases in improving the mental and physical condition of our patients, while the sexual appetite was as effectually destroyed as by castration.

\section{RECENT PROGRESS IN MEDICAL CHEMISTRY.}

BY WILliam B. HiLLS, M. D.

SYNTHESIS OF URIC ACID.

M. HoRBACZEWsKI ${ }^{1}$ has prepared uric acid synthetically in the following manuer: Pure glycocol was finely pulverized and mixed with ten times its weight of pure urea, prepared from ammonium cyanate, and

1 Journal de Pharmacie et de Chimie, January, 1883, page 70, from Berichte der Deutschen Chemischen Gesellschaft, 1882, page 2678. 